\title{
AGHM as A Tool of Evaluating the Parameter from Observed Data Containing Itself and Random Error
}

\author{
Dhritikesh Chakrabarty \\ Department of Statistics, Handique Girls' College, Guwahati, Assam, India \\ E-mail: dhritikesh.c@rediffmail.com,dhritikeshchakrabarty@gmail.com
}

\begin{abstract}
A number of methods like analytical method, stable mid-range method, and shortest interval method had been developed for determining the value of the parameter from observed data containing the parameter itself and random error. Due to (i) huge computational tasks and (ii) limitation of finite set of observed data in determining the appropriate value of the parameter involved in these methods, three more methods have recently been developed for the same purpose. These three methods are respectively based on Arithmetic-Geometric Mean (abbreviated as AGM), Arithmetic-Harmonic Mean (abbreviated as AHM), and Geometric-Harmonic Mean (abbreviated as GHM). Due to the variation occured in accuracy of values of the parameter yielded by these three methods, one more method has been developed in this study for determining the value of the said parameter with an objective of finding more accurate value of the parameter. The method is based on Arithmetic-Geometric-Harmonic Mean (abbreviated as AGHM). This paper describes the derivation of the method and one numerical application of the method in determining the central tendency, which can be represented by the said parameter, of sex ratio in the populations of the different states of India.
\end{abstract}

Keywords: AGHM, observed data, parameter, random error, Sex ratio,; central tendency

\section{Introduction}

In the case of experimental research or survey research, sometimes the observed numerical data

$$
x_{1}, x_{2}, \ldots \ldots \ldots \ldots, x_{N}
$$


are found to be composed of some parameter $\mu$ and random errors $\varepsilon_{i}$.

In this situation, the numerical data can be expressed as

$$
x_{i}=\mu+\varepsilon_{i}, \quad(i=1,2, \ldots \ldots \ldots, N)
$$

[Chakrabarty $(2014 a, 2014 b, 2014 c, 2015 a, 2015 b, 2015 c, 2015 d, 2015 e, 2015 f, 2015 g, 2017 b)]$,. The existing statistical methods of estimation namely least squares method, maximum likelihood method, minimum variance unbiased method, method of moment and method of minimum chi-square, [Aldrich (2000.), Anders (1999), Barnard (1949), Birnbaum (1962), Ivory (1825), Kendall \& Stuart (1977), Lehmann \& Casella George (1998), Lucien (1990), Walker \& Lev (1965)] provide $\frac{1}{N} \sum_{\mathrm{i}=1}^{N} x_{i}$ as estimator of the parameter $\mu$ which suffers from an error

$$
\frac{1}{N} \sum_{i=1}^{N} \varepsilon_{i}
$$

[Chakrabarty $(2014 a, 2014 b, 2014 c)]$.

A number of attempts had been made on developing method(s) of determining the appropriate value of the parameter $\mu$ involved in the model described by equation (1.1) [Chakrabarty (2014a, 2014b , $2014 c, 2015 a, 2015 b, 2015 c, 2015 d, 2015 e, 2015 f, 2015 g, 2016 a, 2016 b, 2019 a, 2019 c]$. In these studies some methods have been developed for determining the appropriate value of the parameter $\mu$ when $\varepsilon_{i}$ occurs due to random cause.

The first method, developed for the same is based on computing sequence of interval value of $\mu$ with decreasing length of interval and then to find out the shortest interval value of $\mu$ [Chakrabarty (2014a, $2014 b, 2014 c, 2015 d$ )] while the second one is based on stable mid range and median (Chakrabarty , $2015 b$ ) and the third one on the convergence of statistic i.e. some function of the available numerical data (Chakrabarty , 2017a). The fourth one (Chakrabarty , 2018a) has been developed on the basis of Pythagorean means [Kolmogorov (1930), O'Meara (1989), Riedweg (2005), Cornelli, McKirahan \& Macris (2013), de Carvalho (2016), Chakrabarty (2018b , 2018c , 2018d , 2018e , 2018f , 2019d , 2019e , 2019f], 2020a , 2021b)] while the fifth one [Chakrabarty $(2016 c, 2019 b)$ ] for the same is based on the probabilistic convergence of Pythagorean means [Chakrabarty $(2017 b, 2017 b)\}$.

The methods, developed so far, for determining the appropriate value of the parameter from observed data containing the parameter itself and random error involve huge computational tasks. Moreover, a 
finite set of observed data may not yield the appropriate value of the parameter in many situations while the number of observations required in the methods may be too large for obtaining the appropriate value of the parameter. However, the appropriate value of theparameter is not perfectly attainable in practical situation. What one can expect is to obtain that value which is more and more close to the appropriate value of the parameter. In order to obtain such value of parameter, three methods have already been developed which involves lesser computational tasks than those involved in the earlier methods as well as which can be applicable in the case of finite set of data [Chakrabarty $(2019 g, 2020 b, 2020 c, 2020 d)$ ]. The methods developed are based on the concepst of Arithmetic-Geometric Mean (abbreviated as AGM) [Chakrabarty $(2019 g$, 2020b , 2021a , 2021e)], Arithmetic-Harmonic Mean(abbreviated as AHM) (Chakrabarty , 2020c , 2021a , 2021c , 2021d , 2021e) and Geometric-Harmonic Mean (abbreviated as GHM) [Chakrabarty , 2020d , 2021a , 2021e)] respectively. However, It has been found that

\section{$A G M>A H M>G H M$}

This means, the accuracy of value of the parameter yielded by $A G M, A H M \& G H M$ is different. Moreover, none of them may yield reasonably accurate value of the parameter. Accordingly, one more method has been developed for determining the value of the said parameter with an objective of finding reasonably accurate value of the parameter. The method is based on Arithmetic-Geometric-Harmonic Mean (abbreviated as AGHM) [Chakrabarty $(2020 e, 2021 a, 2021 e$ ]. This paper describes the derivation of the method and one numerical application of the method in determining the central tendency, which can be represented by the said parameter, of sex ratio in the populations of the states in India.

\section{Arithmetic-Geometric-Harmonic Mean (AGHM)}

Let $a_{0}, g_{0} \& h_{0}$ be respectively the $A M$, the $G M \&$ the $H M$ of $n$ numbers (or values or observations)

$$
x_{1}, x_{2}, \ldots \ldots \ldots \ldots, x_{N}
$$

i.e.

$$
\begin{gathered}
A M\left(x_{1}, x_{2}, \ldots . \ldots \ldots ., x_{N}\right)=\frac{1}{N} \sum_{i=1}^{N} x_{\mathrm{i}}=a_{0} \\
G M\left(x_{1}, x_{2}, \ldots . . . \ldots ., x_{N}\right)=\left(\prod_{i=1}^{N} x_{i}\right)^{1 / N}=g_{0}
\end{gathered}
$$




$$
\& H M\left(x_{1}, x_{2}, \ldots \ldots \ldots \ldots, x_{N}\right)=\left(\frac{1}{N} \sum_{i=1}^{N} x_{\mathrm{i}}^{-1}\right)^{-1}=h_{0}
$$

Then,

$$
h_{0} \leq g_{0} \leq a_{0}
$$

Let us define the three sequences $\left\{a^{\prime \prime \prime}{ }_{n}\right\},\left\{g^{\prime \prime \prime \prime}{ }_{n}\right\} \&\left\{h^{\prime \prime \prime}{ }_{n}\right\}$ respectively by

$$
\begin{aligned}
a^{\prime \prime \prime \prime} & =1 / 3\left(a^{\prime \prime \prime}{ }_{n-1}+g^{\prime \prime \prime}{ }_{n-1}+h^{\prime \prime \prime}{ }_{n-1}\right), \\
g^{\prime \prime \prime \prime}{ }_{n} & \left.=\left(a^{\prime \prime \prime}{ }_{n-1} g^{\prime \prime \prime}{ }_{n-1} h^{\prime \prime \prime}{ }_{n-1}\right)^{1 / 3}\right) \\
\& h_{n}^{\prime \prime \prime} & \left.=\left\{1 / 3\left(a^{\prime \prime \prime}{ }_{n-1}^{-1}+g^{\prime \prime \prime}{ }_{n-1}^{-1}+h^{\prime \prime \prime}{ }_{n-1}^{-1}\right)\right\}^{-1}\right)
\end{aligned}
$$

where the square cube takes the principal value.

For $n=1$, we have

$$
h^{\prime \prime \prime}{ }_{1} \leq g^{\prime \prime \prime}{ }_{1} \leq a^{\prime \prime \prime}{ }_{1}
$$

Since $a^{\prime \prime \prime}{ }_{1}, g^{\prime \prime \prime}{ }_{1} \& h^{\prime \prime \prime}{ }_{1}$ are respectively the $A M$, the $G M \&$ the $H M$ of

$$
a_{0}, g_{0} \& h_{0}
$$

therefore, each of $a^{\prime \prime \prime}{ }_{1}, g^{\prime \prime \prime}{ }_{1} \& h^{\prime \prime \prime}{ }_{1}$ lies between the maximum $a_{0}$ and the minimum $h_{0}$ of $a_{0}, g_{0}$ $\& h_{0}$..

Therefore,

$$
h_{0} \leq h^{\prime \prime \prime}{ }_{1} \leq g^{\prime \prime \prime}{ }_{1} \leq a^{\prime \prime \prime}{ }_{1} \leq a_{0}
$$

By the similar logic, we have for $n=2$ that

$$
h_{0} \leq h^{\prime \prime \prime}{ }_{1} \leq h^{\prime \prime \prime}{ }_{2} \leq g^{\prime \prime \prime}{ }_{2} \leq a^{\prime \prime \prime}{ }_{2} \leq a^{\prime \prime \prime}{ }_{1} \leq a_{0}
$$

Proceeding with the same logic, one can obtain at the $n^{\text {th }}$ step that

$$
h_{0} \leq h^{\prime \prime \prime}{ }_{1} \leq h^{\prime \prime \prime}{ }_{2} \leq \ldots \ldots . . . \leq h^{\prime \prime \prime}{ }_{n} \leq h^{\prime \prime \prime}{ }_{n+1} \leq g^{\prime \prime \prime}{ }_{n+1} \leq a^{\prime \prime \prime}{ }_{n+1} \leq a^{\prime \prime \prime}{ }_{n} \leq \ldots . .
$$

$$
\cdots \ldots . a^{\prime \prime \prime}{ }_{2} \leq a^{\prime \prime \prime}{ }_{1} \leq a_{0}
$$

This inequality implies that the values of $a^{\prime \prime \prime \prime}{ }_{n}, g^{\prime \prime \prime}{ }_{n} \& h^{\prime \prime \prime}{ }_{n}$ have been increasing starting from $h_{0}$ and have been decreasing starting from $a_{0}$.

This means that the values of $a^{\prime \prime \prime}{ }_{n}, g^{\prime \prime \prime \prime}{ }_{n} \& h^{\prime \prime \prime}{ }_{n}$ will be more and more close as $n$ becomes more and more large.

Thus, there exists a finite real number $M_{A G H}$ such that 


$$
\left\{a_{n}^{\prime \prime \prime}\right\},\left\{g_{n}^{\prime \prime \prime}\right\} \&\left\{h_{n}^{\prime \prime \prime}\right\} \text { converges to } M_{A G H} \text { as } n \text { approaches infinity. }
$$

This common converging point (value) $M_{A G H}$ can be termed as Arithmetic-Geometric-Harmonic Mean of $x_{1}, x_{2}, \ldots \ldots \ldots \ldots, x_{N}$.

Accordingly, Arithmetic-Geometric-Harmonic Mean can be defined as follows:

\section{Definition (2.1):}

Let $a_{0}, g_{0} \& h_{0}$ be respectively AM, GM \& HM of the $n$ numbers (or values or observations)

$$
x_{1}, x_{2}, \ldots \ldots \ldots . ., x_{N}
$$

Then, the three sequences $\left\{a^{\prime \prime \prime}{ }_{n}\right\},\left\{g^{\prime \prime \prime}{ }_{n}\right\} \&\left\{h^{\prime \prime \prime}{ }_{n}\right\}$ defined by

$$
\begin{aligned}
& \left.a_{n+1}^{\prime \prime \prime}=1 / 3\left(a_{n}^{\prime \prime \prime}+g_{n}^{\prime \prime \prime}{ }_{n}+h_{n}^{\prime \prime \prime}\right), \quad\right) \\
& \left.g^{\prime \prime \prime}{ }_{n+1}=\left(a^{\prime \prime \prime}{ }_{n} g^{\prime \prime \prime}{ }_{n} h_{n}^{\prime \prime \prime}\right)^{1 / 3}\right) \\
& \left.\& h_{n+1}^{\prime \prime \prime}=\left\{1 / 3\left(a^{\prime \prime \prime}{ }_{n}^{-1}+g^{\prime \prime \prime \prime}{ }^{-1}+h^{\prime \prime \prime}{ }_{n}^{-1}\right)\right\}^{-1}\right)
\end{aligned}
$$

respectively converge to a common limit (say, $M_{A G H}$ ) which is can be termed as the Arithmetic-

Geometric-Harmonic Mean (abbreviated by $A G H M$ of $x_{1}, x_{2}, \ldots \ldots \ldots \ldots, x_{N}$

and is denoted here by $\operatorname{AGHM}\left(x_{1}, x_{2}, \ldots \ldots \ldots . ., x_{N}\right)$

$$
\text { i.e. } \quad A G H M\left(x_{1}, x_{2}, \ldots \ldots \ldots . ., x_{N}\right)=M_{A G H}
$$

\section{E AGHM as a Tool of Evaluation of $\mu$}

If the observations

$$
x_{1}, x_{2}, \ldots \ldots \ldots \ldots, x_{N}
$$

are composed of some parameter $\mu$ and random errors then the observations can be expressed as

$$
\left.x_{i}=\mu+\varepsilon_{i} \quad, \quad(i=1,2, \ldots \ldots \ldots, N) \quad\right)
$$

where

$$
\varepsilon_{1}, \varepsilon_{2}, \ldots \ldots \ldots ., \varepsilon_{N}
$$

are the random errors associated to

$$
x_{1}, x_{2}, \ldots \ldots \ldots \ldots, x_{N}
$$

Respectively, which assume positive real values and negative real values in random order. 
In this case,

$$
A M\left(x_{1}, x_{2}, \ldots \ldots \ldots . . ., x_{N}\right) \rightarrow \mu \text { as } N \rightarrow \infty
$$

On the other hand, if the observations

$$
x_{1}, x_{2}, \ldots \ldots \ldots \ldots, x_{N}
$$

are composed of some parameter $\mu$ and random errors then the observations can also be expressed as

$$
x_{i}=\mu \varepsilon_{i}{ }^{\prime}, \quad(i=1,2, \ldots \ldots \ldots \ldots, N)
$$

where

$$
\varepsilon_{1}{ }^{\prime}, \varepsilon_{2}{ }^{\prime}, \ldots \ldots \ldots \ldots \ldots, \varepsilon_{N}{ }^{\prime}
$$

are the random errors associated to

$$
x_{1}, x_{2}, \ldots \ldots \ldots \ldots, x_{N}
$$

respectively which assume positive real values in $(0,1)$ and in $(1, \infty)$ in random order.

In this case,

$$
G M\left(x_{1}, x_{2}, \ldots \ldots \ldots . . . x_{N}\right) \rightarrow \mu \quad \text { as } \quad N \rightarrow \infty
$$

Again since the observations

$$
x_{1}, x_{2}, \ldots \ldots \ldots \ldots, x_{N}
$$

consist of $\mu$ and random errors,

therefore, the reciprocals

$$
x_{1}^{-1}, x_{2}^{-1}, \ldots \ldots \ldots \ldots \ldots, x_{N}^{-1}
$$

are composed of $\mu^{-1}$ and random errors different from the respective random errors

$$
\varepsilon_{1}, \varepsilon_{2}, \ldots \ldots \ldots \ldots, \varepsilon_{N}
$$

provided $x_{1}, x_{2}, \ldots \ldots \ldots \ldots, x_{N}$ are all different from zero.

In this case thus

$$
x_{i}^{-1}=\mu^{-1}+\varepsilon_{i}^{\prime \prime} \quad, \quad(i=1,2, \ldots \ldots \ldots \ldots, N)
$$

where

$$
\varepsilon_{1}^{\prime \prime}, \varepsilon_{2}^{\prime \prime}, \ldots \ldots \ldots \ldots, \varepsilon_{N}^{\prime \prime}
$$

are the random errors associated to 


$$
x_{1}^{-1}, x_{2}^{-1}, \ldots \ldots \ldots \ldots . . . . ., x_{N}^{-1}
$$

respectively which assume positive real values and negative real values in random order.

In this case,

$$
H M\left(x_{1}, x_{2}, \ldots \ldots \ldots . . ., x_{N}\right) \rightarrow \mu \text { as } N \rightarrow \infty
$$

This implies that the common converging value of

$$
\begin{gathered}
A M\left(x_{1}, x_{2}, \ldots . . . ., x_{N}\right), \\
\operatorname{GM}\left(x_{1}, x_{2}, \ldots . . . . ., x_{N}\right) \\
\& \operatorname{HM}\left(x_{1}, x_{2}, \ldots . . . ., x_{N}\right)
\end{gathered}
$$

as $N \rightarrow \infty$,

is the value of $\mu$.

It is to be noted that a finite set of observed values may not be sufficient for obtaining the common converging value.

However, the three sequences $\left\{a^{\prime \prime \prime}{ }_{n}\right\},\left\{g^{\prime \prime \prime}{ }_{n}\right\} \&\left\{h^{\prime \prime \prime}{ }_{n}\right\}$ defined by (2.1), (2.2) \& (2.3) respectively converge to a common finite real number as $n$ approaches infinity which is the $\operatorname{AGHM}\left(x_{1}, x_{2}\right.$, ,$\left.x_{N}\right)$.

Now, from the model described by Equation (1.1), it follows that

$$
a_{0}=\mu+\delta_{0} \quad, \quad g_{0}=\mu+d_{0} \quad \& \quad h_{0}=\mu+e_{0}
$$

for some real numbers $\delta_{0}, d_{0}, e_{0}$.

Since $\quad a_{0}>g_{0}>h_{0}$

therefore $\delta_{0}>d_{0}>e_{0}$

Thus $\quad a^{\prime \prime \prime}{ }_{1}=\mu+\delta_{1} \quad$ where $\quad \delta_{1}=1 / 3\left(\delta_{0}+d_{0}+e_{0}\right)$

Here, $\delta_{1}<1 / 3\left(\delta_{0}+\delta_{0}+\delta_{0}\right)$, since $d_{0}<\delta_{0} \& e_{0}<\delta_{0}$

i.e. $\delta_{1}<\delta_{0}$

In general, $\quad a_{n+1}^{\prime \prime \prime}=\mu+\delta_{n+1}$ where $\delta_{n+1}=1 / 3\left(\delta_{n}+d_{n}+e_{n}\right)$ 
Now, $\quad \delta_{n+1}=1 / 3\left(\delta_{n}+d_{n}+e_{n}\right)<1 / 3\left(\delta_{n}+\delta_{n}+\delta_{n}\right)$, since $d_{n}<\delta_{n} \& e_{n}<\delta_{n}$ i.e. $\delta_{n+1}<\delta_{n}$

This implies that the value of $a^{\prime \prime \prime}{ }_{n}$ becomes closer and closer to $\mu$ as $n$ becomes larger and larger.

Thus, the converging point (value) of the sequence $\left\{a^{\prime \prime \prime}{ }_{n}\right\}$ becomes closest to $\mu$.

Again the three sequences $\left\{a^{\prime \prime \prime}{ }_{n}\right\},\left\{g^{\prime \prime \prime}{ }_{n}\right\} \&\left\{h^{\prime \prime \prime}{ }_{n}\right\}$ converge to the same point (value) as $n$ approaches infinity which is the $\operatorname{AGHM}\left(x_{1}, x_{2}, \ldots . \ldots \ldots, x_{N}\right)$.

Therefore, the $\operatorname{AGHM}\left(x_{1}, x_{2}, \ldots \ldots \ldots . ., x_{N}\right)$ is that value which is closest to $\mu$.

Hence, $\operatorname{AGHM}\left(x_{1}, x_{2}, \ldots \ldots \ldots . ., x_{N}\right)$ can be regarded as a measure of the value of the parameter $\mu$.

\section{Note}

The parameter $\mu$ can, in this case, be interpreted as the value of the central tendency of $x_{1}, x_{2}$, ,$x_{N}$

Accordingly, $\operatorname{AGHM}\left(x_{1}, x_{2}, \ldots \ldots \ldots . ., x_{N}\right)$ can be regarded as a measure of the central tendency of $x_{1}, x_{2}, \ldots \ldots \ldots \ldots, x_{N}$.

\subsection{Remark (Two Properties of AGHM):}

Property (3.1): If $y_{i}=x_{i}-a$, for finite real $a,(i=1,2, \ldots \ldots \ldots, N)$ then from equation (3.1),

$$
y_{i}=(\mu-a)+\varepsilon_{i}, \quad(i=1,2, \ldots \ldots, N)
$$

This means that if a finite real number $a$ is subtracted from all the observed values, the value of the parameter is decreased by $a$. 
Similarly if a finite real number $a$ is added from all the observed values, the value of the parameter is increased by $a$.

Property (3.2): If $y_{i}=c . x_{i}$, for non-zero finite real $c,(i=1,2, \ldots \ldots ., N)$ then from equation (3.1),

$$
y_{i}=c . \mu+c . \varepsilon_{i}, \quad(i=1,2, \ldots \ldots ., N)
$$

where $c . \varepsilon_{i}(i=1,2$, $, N)$ are also random.

This means that if all the observed values are multiplied by a non-zero finite real number, the value of the parameter is changed by $c$ times.

\section{Application to Numerical Data}

The following table (Table - 1) shows the observed data on the population (sex-wise) of India for different states in 2011, as published in "Census Report" by Register General of India.

Table - 1

Population of India in 2011 (State-wise)

\begin{tabular}{|l|r|r|r|}
\hline \multicolumn{1}{|c|}{ State } & \multicolumn{1}{c|}{ Number of Persons } & \multicolumn{1}{c|}{ Number of Males } & Number of Females \\
\hline Jammu \& Kashmir & $1,25,41,302$ & $66,40,662$ & $59,00,640$ \\
\hline Himachal Pradesh & $68,64,602$ & $34,81,873$ & $33,82,729$ \\
\hline Punjab & $2,77,43,338$ & $1,46,39,465$ & $1,31,03,873$ \\
\hline Chandigarh & $10,55,450$ & $5,80,663$ & $4,74,787$ \\
\hline Uttarakhand & $1,00,86,292$ & $51,37,773$ & $49,48,519$ \\
\hline Haryana & $2,53,51,462$ & $1,34,94,734$ & $1,18,56,728$ \\
\hline Delhi & $1,67,87,941$ & $89,87,326$ & $78,00,615$ \\
\hline Rajasthan & $6,85,48,437$ & $3,55,50,997$ & $3,29,97,440$ \\
\hline Uttar Pradesh & $19,98,12,341$ & $10,44,80,510$ & $9,53,31,831$ \\
\hline Bihar & $10,40,99,452$ & $5,42,78,157$ & $4,98,21,295$ \\
\hline Sikkim & $6,10,577$ & $3,23,070$ & $2,87,507$ \\
\hline Arunachal Pradesh & $13,83,727$ & $7,13,912$ & $6,69,815$ \\
\hline Nagaland & $19,78,502$ & $10,24,649$ & $9,53,853$ \\
\hline Manipur & $28,55,794$ & $14,38,586$ & $14,17,208$ \\
\hline Mizoram & $10,97,206$ & $5,55,339$ & $5,41,867$ \\
\hline Tripura & $36,73,917$ & $18,74,376$ & $17,99,541$ \\
\hline
\end{tabular}


International Journal of Electronics and Applied Research (IJEAR) vol. 7, issue 2, Dec 2020

\begin{tabular}{|l|r|r|r|}
\hline Meghalaya & $29,66,889$ & $14,91,832$ & $14,75,057$ \\
\hline Assam & $3,12,05,576$ & $1,59,39,443$ & $1,52,66,133$ \\
\hline West Bengal & $9,12,76,115$ & $4,68,09,027$ & $4,44,67,088$ \\
\hline Jharkhand & $3,29,88,134$ & $1,69,30,315$ & $1,60,57,819$ \\
\hline Odisha & $4,19,74,218$ & $2,12,12,136$ & $2,07,62,082$ \\
\hline Chhattisgarh & $2,55,45,198$ & $1,28,32,895$ & $1,27,12,303$ \\
\hline Madhya Pradesh & $7,26,26,809$ & $3,76,12,306$ & $3,50,14,503$ \\
\hline Gujarat & $6,04,39,692$ & $3,14,91,260$ & $2,89,48,432$ \\
\hline Daman \& Diu & $2,43,247$ & $1,50,301$ & 92,946 \\
\hline Dadra \& Nagar Haveli & $3,43,709$ & $1,93,760$ & $1,49,949$ \\
\hline Maharashtra & $11,23,74,333$ & $5,82,43,056$ & $5,41,31,277$ \\
\hline Andhra Pradesh & $8,45,80,777$ & $4,24,42,146$ & $4,21,38,631$ \\
\hline Karnataka & $6,10,95,297$ & $3,09,66,657$ & $3,01,28,640$ \\
\hline Goa & $14,58,545$ & $7,39,140$ & $7,19,405$ \\
\hline Lakshadweep & 64,473 & 33,123 & 31,350 \\
\hline Kerala & $3,34,06,061$ & $1,60,27,412$ & $1,73,78,649$ \\
\hline Tamil Nadu & $7,21,47,030$ & $3,61,37,975$ & $3,60,09,055$ \\
\hline Pondicherry & $12,47,953$ & $6,12,511$ & $6,35,442$ \\
\hline Andaman \& Nicobar & $3,80,581$ & $2,02,871$ & $1,77,710$ \\
\hline India & $\mathbf{1 , 2 1 , 0 8 , 5 4 , 9 7 7}$ & $\mathbf{6 2 , 3 2 , 7 0 , 2 5 8}$ & $\mathbf{5 8 , 7 5 , 8 4 , 7 1 9}$ \\
\hline
\end{tabular}

Table $\mathbf{- 2}$ has been prepared for observed values on the two ratios Male/Female \& Female/Male.

Table - 2

\begin{tabular}{|l|l|l|}
\hline \multicolumn{1}{|c|}{ State } & \multicolumn{1}{c|}{$\begin{array}{c}\text { Value of the Ratio } \\
\text { Male/Female }\end{array}$} & \multicolumn{1}{c|}{$\begin{array}{c}\text { Value of the Ratio } \\
\text { Female/Male }\end{array}$} \\
\hline $\begin{array}{l}\text { Jammu \& } \\
\text { Kashmir }\end{array}$ & 1.1254138534125111852273651671683 & 0.88856201384741461016988968870875 \\
\hline $\begin{array}{l}\text { Himachal } \\
\text { Pradesh }\end{array}$ & 1.0293088804926436613751796256809 & 0.97152567023553127871119940330966 \\
\hline Punjab & 1.11718611741734676457868601138 & 0.89510600284914783429585712319405 \\
\hline Chandigarh & 1.2229968385823537712700642603947 & 0.81766360177934533455722165869015 \\
\hline Uttarakhand & 1.0382445737805593956494862402266 & 0.96316419584905755859591305415792 \\
\hline Haryana & 1.1381499179200197558719403869263 & 0.878618874592118673847146598073 \\
\hline Delhi & 1.1521304409972803426396508480421 & 0.86795727672502366109786158864161 \\
\hline Rajasthan & 1.077386518469311558714857879884 & 0.92817200035205763708961523638845 \\
\hline Uttar Pradesh & 1.0959666766496911194331303675474 & 0.91243650131493423988837726768373 \\
\hline Bihar & 1.0894569681498644304609103396449 & 0.91788847952225054362107394324387 \\
\hline Sikkim & 1.1236943796151050235298618816238 & 0.88992168879809329247531494722506 \\
\hline
\end{tabular}


International Journal of Electronics and Applied Research (IJEAR) vol. 7, issue 2, Dec 2020

\begin{tabular}{|l|l|l|}
\hline $\begin{array}{l}\text { Arunachal } \\
\text { Pradesh }\end{array}$ & 1.0658345961198241305435082821376 & 0.93823188292114434272011116216004 \\
\hline Nagaland & 1.0742210801874083323111632505218 & 0.93090707159232088256563955071444 \\
\hline Manipur & 1.0150845888535768920299631387912 & 0.98513957455445833617176866728857 \\
\hline Mizoram & 1.0248621894302476437945104610541 & 0.97574094381990099740878994632108 \\
\hline Tripura & 1.0415856043291039214999824955364 & 0.96007471286444128606000076825568 \\
\hline Meghalaya & 1.0113724418785172369610123540989 & 0.98875543626896326127874988604615 \\
\hline Assam & 1.0441048168517855831597956077024 & 0.95775824788858682201128358123932 \\
\hline West Bengal & 1.0526667948213744061675457587868 & 0.94996821873695430584361430969287 \\
\hline Jharkhand & 1.0543346515488809532602154750904 & 0.9484654597389357492757813425208 \\
\hline Odisha & 1.0216767277963741786589610810708 & 0.97878318336258074151514020087369 \\
\hline Chhattisgarh & 1.0094862433659738915914763831542 & 0.99060289981333128651017560729672 \\
\hline $\begin{array}{l}\text { Madhya } \\
\text { Pradesh }\end{array}$ & 1.0741921997293521487367677330733 & 0.93093209972289388478334723747063 \\
\hline Gujarat & 1.0878399216924771607664276945985 & 0.9192528974705997791133158851059 \\
\hline Daman \& Diu & 1.6170787338884943945947109074086 & 0.61839907918110990612171575704752 \\
\hline $\begin{array}{l}\text { Dadra \& Nagar } \\
\text { Haveli }\end{array}$ & 1.29217267204182755470193199021 & 0.77389037985136251032204789430223 \\
\hline Maharashtra & 1.0759593940486569345112623151307 & 0.92940310343605596519523288750508 \\
\hline $\begin{array}{l}\text { Andhra } \\
\text { Pradesh }\end{array}$ & 1.0072027731513157131279371653056 & 0.99284873578258743089946488568226 \\
\hline Karnataka & 1.0278146308628600560795309711955 & 0.97293808627776643762353811714322 \\
\hline Goa & 1.0274323920462048498411882041409 & 0.97330005141109938577265470682144 \\
\hline Lakshadweep & 1.0565550239234449760765550239234 & 0.94647223983334842858436735802916 \\
\hline Kerala & 0.92224729321594561234305382426448 & 1.0843078720382305015931455433978 \\
\hline Tamil Nadu & 1.0035802105886977594941050244168 & 0.99643256159206485698216349975338 \\
\hline Pondicherry & 0.96391330758747454527714567183158 & 1.0374376949964980220763382208646 \\
\hline $\begin{array}{l}\text { Andaman \& } \\
\text { Nicobar }\end{array}$ & 1.1415846041303246862866467840864 & 0.87597537351321775906857066806002 \\
\hline India & 1.0607325851848778252519531570732 & 0.94274467850509882664736426425148 \\
\hline
\end{tabular}

\section{Central Tendency of the Ratio Male/Female:}

From the observed values on the ratio Male/Female in Table $-\mathbf{3}$ it has been obtained that

$A M$ of Male $/$ Female $=1.0835068016450523020161865887443$,

$G M$ of Male $/$ Female $=1.0784172361960199316030087704149$

$\& H M$ of Male / Female $=1.0740468088974845410059550737324$

The following table (Table - 3) shows the values of $a_{n}^{\prime} \& h_{n}^{\prime}$, in this case, for $n=1,2,3, \ldots \ldots \ldots$. 


\section{Table -3}

Computeed Values of $a^{\prime \prime \prime}{ }_{n}, g^{\prime \prime \prime \prime}{ }_{n} \& h^{\prime \prime \prime}{ }_{n}$ of the Ratio Male / Female

\begin{tabular}{|c|c|c|}
\hline$n$ & Term of sequence & Values of $a_{n}^{\prime \prime \prime}, g_{n}^{\prime \prime \prime} \& h_{n}^{\prime \prime \prime}$ \\
\hline \multirow{3}{*}{1} & $a_{1}^{\prime \prime \prime}$ & $\underline{1.0786} 569489128522582083834776305$ \\
\hline & $g^{\prime \prime \prime}$ & 1.0786500232826463705959730067094 \\
\hline & $h^{\prime \prime \prime}$ & $\underline{1.0786430991879167734854095348694}$ \\
\hline \multirow{3}{*}{2} & $a_{2}^{\prime \prime \prime}$ & 1.0786500237944718007632553397364 \\
\hline & $g_{2}^{\prime \prime \prime}$ & $\underline{1.0786500237796527462927936308012}$ \\
\hline & $h_{2}^{\prime / I}$ & 1.0786500237648336918293636455239 \\
\hline \multirow{3}{*}{3} & $a^{1 / 1} 3$ & $\underline{1.078650023779652746295} 1375386872$ \\
\hline & $g^{\prime \prime \prime}$ & $\underline{1.0786500237796527462950696747305}$ \\
\hline & $h^{\prime \prime \prime}$ & 1.0786500237796527462950018107739 \\
\hline \multirow{3}{*}{4} & $a_{4}^{\prime \prime \prime}$ & 1.0786500237796527462950696747305 \\
\hline & $g_{4}^{\prime \prime}$ & $\underline{1.0786500237796527462950696747305}$ \\
\hline & $h_{4}^{\prime / I}$ & $\underline{1.0786500237796527462950696747305}$ \\
\hline
\end{tabular}

The digits in $a^{\prime \prime \prime}{ }_{n}, g^{\prime \prime \prime}{ }_{n} \& h^{\prime \prime \prime}{ }_{n}$, which are agreed, have been underlined in the above table.

It is obsereved that the values of $a^{\prime \prime \prime}{ }_{n}, g^{\prime \prime \prime}{ }_{n} \& h^{\prime \prime \prime}{ }_{n}$ become identical at $n=4$ which is

\subsection{5}

Therefore, this value can be regarded as the $A G H M$ and consequently the central tendency of the data on the Ratio Male/Female in the context of the states inIndia.

\section{Central Tendency of the Ratio Female/Male:}

From the observed values on Female/Male in Table $-\mathbf{3}$ it has been obtained that

$$
\begin{aligned}
A M \text { of } \text { Female/Male } & =0.9310581175009550726813265197974, \\
G M \text { of Female/Male } & =0.92728488235905168784178691872109 \\
\& H M \text { of Female/Male } & =0.92292913942185992242619179784686
\end{aligned}
$$

The computed values of $\left\{a_{n}^{\prime}\right\} \&\left\{h_{n}^{\prime}\right\}$, in this case, have been shown in the following table Table $-\mathbf{4}$ : 
Table -4

Computeed Values of $a^{\prime \prime \prime}{ }_{n}, g^{\prime \prime \prime}{ }_{n} \& h^{\prime \prime \prime}{ }_{n}$ of the Ratio Male / Female

\begin{tabular}{|c|c|l|}
\hline \multirow{4}{*}{$n$} & Term of sequence & \multicolumn{1}{c|}{ Values of $a^{\prime \prime \prime}{ }_{n}, g^{\prime \prime \prime \prime}{ }_{n} \& h^{\prime \prime \prime}{ }_{n}$} \\
\hline \multirow{4}{*}{1} & $a^{\prime \prime \prime}{ }_{1}$ & $\underline{0.92709071309395556098310174545512}$ \\
\cline { 2 - 3 } & $g^{\prime \prime \prime}{ }_{1}$ & $\underline{0.9270} 8476189219240096038081993126$ \\
\cline { 2 - 3 } & $h^{\prime \prime \prime}{ }_{1}$ & $\underline{0.92707880944712926028363970338239}$ \\
\hline \multirow{4}{*}{2} & $a^{\prime \prime \prime}{ }_{2}$ & $\underline{0.92708476147775907407570742292292}$ \\
\cline { 2 - 3 } & $g^{\prime \prime \prime}{ }_{2}$ & $\underline{0.92708476146502230193490281506759}$ \\
\cline { 2 - 3 } & $h^{\prime \prime \prime}$ & $\underline{0.92708476145228552978840450686974}$ \\
\hline \multirow{3}{*}{3} & $a^{\prime \prime \prime}{ }_{3}$ & $\underline{0.92708476146502230193300491495342}$ \\
\cline { 2 - 3 } & $g^{\prime \prime \prime}{ }_{3}$ & $\underline{0.92708476146502230193294658682228}$ \\
\cline { 2 - 3 } 4 & $h^{\prime \prime \prime}{ }_{3}$ & $\underline{0.9270847614650223019328882586911}$ \\
\cline { 2 - 3 } & $a^{\prime \prime \prime}$ & $\underline{0.92708476146502230193294658682227}$ \\
\cline { 2 - 3 } & $g^{\prime \prime \prime}$ & $\underline{0.92708476146502230193294658682227}$ \\
\cline { 2 - 3 } & $h^{\prime \prime \prime}{ }_{4}$ & $\underline{0.92708476146502230193294658682227}$ \\
\hline
\end{tabular}

The digits in $a^{\prime \prime \prime}{ }_{n}, g^{\prime \prime \prime}{ }_{n} \& h^{\prime \prime \prime}{ }_{n}$, which are agreed, have been underlined in the above table.

It is observed that the values of $a^{\prime \prime \prime}{ }_{n}, g^{\prime \prime \prime}{ }_{n} \& h^{\prime \prime \prime}{ }_{n}$ become identical at $n=4$ which is

$$
0.92708476146502230193294658682227
$$

Therefore, this value can be regarded as the $A G H M$ and consequently the central tendency of the data on the Ratio Female/Male in the context of the states inIndia.

\section{Discussions and Conclusion:}

$\mathrm{T}$ The methods developed so far, for determining appropriate value of parameter from observed data containing the parameter itself and random error involve huge computational tasks. The method, based on 
AGHM, described here involves lesser computational tasks than those involved in the methods developed so far.

Moreover, a finite set of observed data may not yield the appropriate value of the parameter in many situations while the number of observations required in the methods may be too large for obtaining the appropriate value of the parameter. The method, based on AGHM, can be applicable in the case of finite set of data.

In this connection it is to be mentioned that AGHM exists only when the observed values are strictly positive. In the situation where the numerical values in the data are found not to be strictly positive, the central tendency of the data can be determined by the application of the two properties of AGHM namely Property (3.1) \& Property (3.2) for which suitable change of origin and scale is required to be applied in order to convert the numerical values in the data into strictly positive ones.

It is to be noted that AGHM may not be able to yield the actual value of the parameter. However, it can at least yield that value which is very close to the actual value of the parameter.

If $\mu$ is the central tendency of

$$
x_{1}, x_{2}, \ldots \ldots \ldots . ., x_{N}
$$

then the central tendency of

$$
x_{1}^{-1}, x_{2}^{-1}, \ldots \ldots \ldots \ldots, x_{N}^{-1}
$$

should logically be $\mu-1$.

It is observed in the in the above example that the AGHM of the ratio Male /Female is 1.0786500237796527462950696747305

and of the ratio Female/Male is

0.92708476146502230193294658682227

These two values are reciprocals each other i.e.

$(1.0786500237796527462950696747305)^{-1}=0.92708476146502230193294658682227$

\& $(0.92708476146502230193294658682227)^{-1}=1.0786500237796527462950696747305$

It is to be noted that AM of the ratio Male/Female which is 1.0835068016450523020161865887443 and of the ratio Female/Male which is 0.9310581175009550726813265197974 are not reciprocals each other. 
Similarly, HM of the ratio Male/Female which is 1.0740468088974845410059550737324 and of the ratio Female/Male which is 0.92292913942185992242619179784686 are also not reciprocals each other. Thus, AGHM can logically be regarded as a measure of central tendency of data which is more meritorious than AM \& HM .

Of course, GM of the ratio Male/Female which is 1.0784172361960199316030087704149 and of the ratio Female/Male which is 0.92728488235905168784178691872109 are reciprocals each other. This implies that GM can also logically be regarded as a measure of central tendency of data which is more meritorious than AM \& HM. However, which one of AHM and GM is more meritorious as ameasure of central tendency of data is still unknown.

On the whole, the two values

1.0786500237796527462950696747305 \& 0.92708476146502230193294658682227

can logically be regarded as the respective values of central tendency of the Ratio Male/Female and the Ratio Female/Male of the states in India while the overall values of these two ratios in India (combing the states) are

\section{$1.0607325851848778252519531570732 \quad \& \quad 0.94274467850509882664736426425148$}

Respectively at this stage.

However, it is yet to be determined the size of errors or discrepancies in values obtained by AGHM. It is also to be assessed the performance of AGHM by applying it in the data with various sample sizes.

It has already been derived that each of AGM, AHM \& GHM converges to $\mu$ in the model described by the equation (1.) as $\mathrm{n} \rightarrow \infty$ [Chakrabarty (2020b, 2020c , 2020d)].

Thus, there is necessity of study on the comparison of the accuracy of the findings yielded by AGM, AHM, GHM \& AGHM.

Hayakawa, M. and Y. Tanaka (1978), On the propagation of low-latitude whistlers, Rev. Geophys. Space Phys., 16, 111-123.

\section{Reference}

Aldrich John, Fisher's Inverse Probability of 1930, International Statistical Review, Vol. 68, pp. 155 $172,2000$.

Anders Hald, On the History of Maximum Likelihood in Relation to Inverse Probability and Least Squares, Statistical Science, Vol. 14, pp. 214 - 222, 1999. 
Barnard G. A., Statistical Inference, Journal of the Royal Statistical Society, Series B, Vol. 11, pp. 115 $149,1949$.

Birnbaum Allan, On the Foundations of Statistical Inference, Journal of the American Statistical Association, Vol. 57, pp. 269 - 306, 1962.

Chakrabarty Dhritikesh, Determination of Parameter from Observations Composed of Itself and Errors, International Journal of Engineering Science and Innovative Technology, 3(2), (ISSN : 2139 - 5967), $304-311,2014 a$.

Chakrabarty Dhritikesh, Analysis of Errors Associated to Observations of Measurement Type, International Journal of Electronics and Applied Research (ISSN : 2395 - 0064), 1(1), 15 - 28, $2014 b$. Available at http://eses.net.in/ESES Journal.

Chakrabarty Dhritikesh, Observation Composed of a Parameter and Random Error: An Analytical Method of Determining the Parameter, International Journal of Electronics and Applied Research (ISSN : 2395 - 0064), 1(2), 20 - 38, 2014c. Available at http://eses.net.in/ESES Journal.

Chakrabarty Dhritikesh, Observation Consisting of Parameter and Error: Determination of Parameter, Proceedings of the World Congress on Engineering 2015, (WCE 2015, July 1 - 3, 2015, London, U.K.), ISBN: 978-988-14047-0-1, ISSN: 2078-0958 (Print); ISSN: 2078-0966 (Online), Vol. II, 680 - 684, $2015 a$.

Chakrabarty Dhritikesh: "Observation Consisting of Parameter and Error: Determination of Parameter," Lecture Notes in Engineering and Computer Science (ISBN: 978-988-14047-0-1), London, 680 - 684, 2015b. Available at https://www.researchgate.net/profile/Dhritikesh_Chakrabarty/stats.

Chakrabarty Dhritikesh, Central Tendency of Annual Extremum of Surface Air Temperature at Guwahati, J. Chem. Bio. Phy. Sci. (E- ISSN : 2249 - 1929), Sec. C, 5(3), 2863 - 2877, $2015 c$.

Chakrabarty Dhritikesh, Central Tendency of Annual Extremum of Surface Air Temperature at Guwahati Based on Midrange and Median, J. Chem. Bio. Phy. Sci. (E- ISSN : 2249 - 1929), Sec. D, 5(3), 3193 3204, 2015d.

Chakrabarty Dhritikesh, Observation Composed of a Parameter and Random Error: Determining the Parameter as Stable Range, International Journal of Electronics and Applied Research (ISSN : 2395 0064), 2(1), 35 - 47, 2015e.

Chakrabarty Dhritikesh, A Method of Finding Appropriate value of Parameter from Observation Containing Itself and Random Error, Indian Journal of Scientific Research and Technology, (E-ISSN: 2321-9262), 3(4), $14-21,2015 f$. 
Chakrabarty Dhritikesh, Theoretical Model Modified For Observed Data: Error Estimation Associated To Parameter, International Journal of Electronics and Applied Research (ISSN : 2395 - 0064), 2(2), 29 45, 2015g. Available at http://eses.net.in/ESES Journal.

Chakrabarty Dhritikesh, Impact of Error Contained in Observed Data on Theoretical Model: Study of Some Important Situations, International Journal of Advanced Research in Science, Engineering and Technology, (ISSN : 2350 - 0328), 3(1), 1255 - 1265, $2016 a$.

Chakrabarty Dhritikesh, Theoretical Model and Model Satisfied by Observed Data: One Pair of Related Variables, International Journal of Advanced Research in Science, Engineering and Technology, (ISSN : $2350-0328), 3(2), 1527-1534,2016 b$.

Chakrabarty Dhritikesh, Pythagorean Mean: Concept behind the Averages and Lot of Measures of Characteristics of Data, NaSAEAST- 2016, Abstract ID: CMAST_NaSAEAST (Inv)-1601), $2016 c$. Available at https://www.researchgate.net/profile/Dhritikesh_Chakrabarty/stats .

Chakrabarty Dhritikesh, Numerical Data Containing One Parameter and Random Error: Evaluation of the Parameter by Convergence of Statistic, International Journal of Electronics and Applied Research (ISSN : 2395 - 0064), 4(2), 59 - 73, 2017a. Available at http://eses.net.in/ESES Journal.

Chakrabarty Dhritikesh, Variable(s) Connected by Theoretical Model and Model for Respective Observed Data, $3^{\text {rd }}$ International Conference on Fuzzy Systems and Data Mining (FSDM 2017), Paper ID: FSDM2220. 2017b. Available at https://www.researchgate.net/profile/Dhritikesh_Chakrabarty/stats .

Chakrabarty Dhritikesh, Objectives and Philosophy behind the Construction of Different Types of Measures of Average, NaSAEAST- 2017, Abstract ID: CMAST_NaSAEAST (Inv)-1701), 2017c. Available at https://www.researchgate.net/profile/Dhritikesh_Chakrabarty/stats .

Chakrabarty Dhritikesh, Observed Data Containing One Parameter and Random Error: Evaluation of the Parameter Applying Pythagorean Mean, International Journal of Electronics and Applied Research (ISSN : 2395 - 0064), 5(1), 32 - 45, 2018a. Online (http://eses.net.in/ESES Journal). Available at http://eses.net.in/ESES Journal.

Chakrabarty Dhritikesh, Derivation of Some Formulations of Average from One Technique of Construction of Mean, American Journal of Mathematical and Computational Sciences, 3(3), 62 - 68, $2018 b$.

Chakrabarty Dhritikesh, One Generalized Definition of Average: Derivation of Formulations of Various Means, Journal of Environmental Science, Computer Science and Engineering \& Technology, Section C, (E-ISSN : $2278-179 \mathrm{X}), 7(3), 212-225,2018 c$. 
Chakrabarty Dhritikesh, $f_{H}$ - Mean: One Generalized Definition of Average, Journal of Environmental Science, Computer Science and Engineering \& Technology, Section C, (E-ISSN : 2278 - 179 X), 7(4), $301-314,2018 d$. Also available in www.jecet.org.

Chakrabarty Dhritikesh, General Technique of Defining Average, NaSAEAST- 2018, Abstract ID: CMAST_NaSAEAST-1801 (I), 2018e. Available at https://www.researchgate.net/profile/Dhritikesh_Chakrabarty/stats .

Chakrabarty Dhritikesh, Generalized $f_{G}$ - Mean: Derivation of Various Formulations of Average, American Journal of Computation, Communication and Control, 5(3), 101 - 108, 2018f. Available in http://www.aascit.org/journal/ajmcs .

Chakrabarty Dhritikesh, Significance of Change of Rainfall: Confidence Interval of Annual Total Rainfall, Journal of Chemical, Biological and Physical Sciences (E- ISSN : 2249 - 1929), Sec. C, 9(3), 151 - 166, 2019a. Available at: www.jcbsc.org.

Chakrabarty Dhritikesh, Observed Data Containing One Parameter and Random Error: Probabilistic Evaluation of Parameter by Pythagorean Mean, International Journal of Electronics and Applied Research (ISSN : 2395 - 0064), 6(1), 24 - 40, 2019b. Available at http://eses.net.in/ESES Journal.

Chakrabarty Dhritikesh, Significance of Change in Surface Air Temperature in the Context of India, Journal of Chemical, Biological and Physical Sciences (E- ISSN : 2249 - 1929), Sec. C, 9(4), 251 - 261, 2019c. Online available at: www.jcbsc.org .

Chakrabarty Dhritikesh, One General Method of Defining Average: Derivation of Definitions/Formulations of Various Means, Journal of Environmental Science, Computer Science and Engineering \& Technology, Section C, (E-ISSN : 2278 - 179 X), 8(4), 327 - 338, 2019d. Also available in www.jecet.org .

Chakrabarty Dhritikesh, A General Method of Defining Average of Function of a Set of Values, Aryabhatta Journal of Mathematics \& Informatics \{ISSN (Print) : 0975-7139, ISSN (Online) : 23949309\}, 11(2), 269 - 284, 2019e. Also available in www.abjni.com .

Chakrabarty Dhritikesh, Pythagorean Geometric Mean: Measure of Relative Change in a Group of Variables, NaSAEAST- 2019, Abstract ID: CMAST_NaSAEAST -1902 (I), 2019f. Available at https://www.researchgate.net/profile/Dhritikesh_Chakrabarty/stats .

Chakrabarty Dhritikesh, Arithmetic-Geometric Mean: Evaluation of Parameter from Observed Data Containing Itself and Random Error, International Journal of Electronics and Applied Research (ISSN : 2395 - 0064), 6(2), 24 - 40, 2019g. Available at http://eses.net.in/ESES Journal.

Chakrabarty Dhritikesh, Definition / Formulation of Average from First Principle", Journal of Environmental Science, Computer Science and Engineering \& Technology, Section C, (E-ISSN : 2278 179 X), 9(2), $151-163,2020 a$. Availableat www.jecet.org . 
Chakrabarty Dhritikesh, AGM: A Technique of Determining the Value of Parameter from Observed Data Containing Itself and Random Error, Journal of Environmental Science, Computer Science and Engineering \& Technology, Section C, (E-ISSN : 2278 - 179 X), 9(3), 473 - 486, 2020b. Available at www.jecet.org .

Cornelli G., McKirahan R. \& Macris C, On Pythagoreanism, Berlin, Walter de Gruyter, 2013.

de Carvalho Miguel, Mean, what do you Mean?, The American Statistician, 70, 764 -776, 2016.

David A. Cox, The Arithmetic-Geometric Mean of Gauss, In J.L. Berggren; Jonathan M. Borwein; Peter Borwein (eds.). Pi: A Source Book. Springer. p. 481. ISBN 978-0-387-20571-7. first published in L'Enseignement Mathématique, t. 30 (1984), p. 275-330, 2004

Hazewinkel, Michiel, ed., Arithmetic-geometric mean process, Encyclopedia of Mathematics, Springer Science+Business Media B.V. / Kluwer Academic Publishers, ISBN 978-1-55608-010-4, 2001.

Ivory, On the Method of Least Squares, Phil. Mag., LXV, 3 - 10, 1825.

Kendall M. G. and Stuart A, Advanced Theory of Statistics, Vol. $1 \& 2$, $4^{\text {th }}$ Edition, New York, Hafner Press, 1977.

Kolmogorov Andrey, On the Notion of Mean, Mathematics and Mechanics, 199(1), 144 - 146, 1930.

Lehmann Erich L. \& Casella George, Theory of Point Estimation, 2nd ed. Springer. ISBN 0 - 387 $98502-6,1998$.

Lucien Le Cam, Maximum likelihood — An introduction, ISI Review, 58 (2), 153 -171, 1990.

Michiel ed. Hazewinkel, Normal Distribution, Encyclopedia of Mathematics, Springer, ISBN 978 - 1 $55608-010-4,2001$.

Walker Helen M. \& Lev J., Statistical Inference, Oxford \& IBH Publishing Company, 1965.

O'Meara Dominic J., Pythagoras Revived: Mathematics and Philosophy in Late Antiquity, ISBN $\underline{0-19-}$ 823913-0, Clarendon Press, Oxford, 1989.

Riedweg Christoph, Pythagoras: his life, teaching, and influence (translated by Steven Rendall in collaboration with Christoph Riedweg and Andreas Schatzmann, Ithaca), ISBN 0-8014-4240-0, Cornell University Press, 2005. 